\title{
NUMERICAL SIMULATION OF A CAVITATING PULSATING WATER JET USED FOR REMOVING CONTAMINANTS FROM METAL SURFACES
}

\begin{abstract}
Summary
The paper presents an environmentally friendly method for cleaning metal surfaces from contaminants. In this method, the contaminants are removed from surfaces by a cavitating pulsating water jet generated in the nozzle and directed at the surface. The cavitation-generating effectiveness of three various design nozzles was investigated numerically using the SolidWorks 2015 Flow Simulation software. The volume fraction of the vapour generated in the flow inside the nozzles was determined. Selected nozzle was studied experimentally in respect of efficiency of abrasive particle removal. After having carried out experiments to test the removal efficiency of the method, it was established that the water that has remained on the cleaned surface decreases its effectiveness. To solve this problem, a prototype of a cavitation-generating head with a water removal system was created and studied numerically.
\end{abstract}

Key words: $\quad$ cavitation, clean surface, microbubbles, nozzle

\section{Introduction}

Industry needs a variety of surface treatments and finishes, such as cutting, grinding, etc. However, most of these processes produce contaminants on the surfaces, which may adversely affect the product quality. For instance, contaminated surfaces cannot be used in some industries, such as optics, medicine, and electronics, without being cleaned. However, due to increasingly stringent environmental requirements, traditional cleaning methods (especially those which utilize hazardous cleaning solvents [1, 2]) cannot be used in most cases. Therefore, new, environmentally friendly surface cleaning techniques are being developed to solve the environmental issues. One of the alternatives to traditional cleaning methods is the use of cavitating water jet to remove contaminants from surfaces [3]. It is widely known that cavitation has a number of harmful effects, such as erosion wear, increased noise, and reduced efficiency [4, 5]. Cavitation occurs when the local pressure in a liquid drops below the critical pressure (or saturated vapour pressure) due to high local velocities or accelerations; this, in turn, causes cavitation nuclei (or microbubbles formed in the liquid) to grow exponentially [6-8]. When the pressure along the path of cavitation bubbles is restored to the original value, volume implosions occur, which results in pressure pulses and shock 
waves [9]. Figure 1 shows the components of the proposed surface cleaning system which utilises a cavitating water jet.

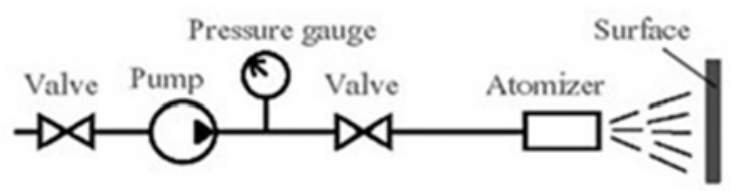

Fig. 1 A schematic diagram of surface cleaning using a cavitating water jet [3]

The proposed technique utilizes the cavitation phenomenon as a widely used ultrasonic surface cleaning process [10], but it does not utilise expensive equipment such as ultrasonic generators and baths. Water under pressure is supplied to the surface being cleaned (Fig. 1) through the atomizer (nozzle) that generates cavitation in the water jet. Cavitation-induced microbubbles act on various contaminants which adhere to different surfaces, such as plastics, glass, ceramics, and metals [3]. Cavitation-induced erosion exhibits great destructive power which can be used in various engineering applications [11-16], including mining, depolymerisation, waste treatment, cutting, etc. Cavitating jets in which a lot of bubbles are formed use the energy released by the collapse of bubbles to increase the impact force of the jet [17].

The proposed surface cleaning method requires the water pressure range 8 to $15 \mathrm{MPa}$, which increases the cost of equipment and energy consumption. In order to reduce these costs, special design nozzles that generate cavitation at lower supply pressures were developed [1820]. The eddying flow in such nozzles pulsates and thus acts like ultrasonic waves in an ultrasonic cleaning process [3].

The purpose of this research was to investigate various designs of nozzles that could be used in a head to generate cavitation in the water jet and direct it at the surface. An optimum nozzle design should generate the maximum number of microbubbles at the minimum pressure of supplied water. It is also important to determine the place inside the nozzle where cavitation starts to occur. In case it occurs too far away from the outlet, inner surfaces of the nozzle can be damaged by cavitation-induced erosion.

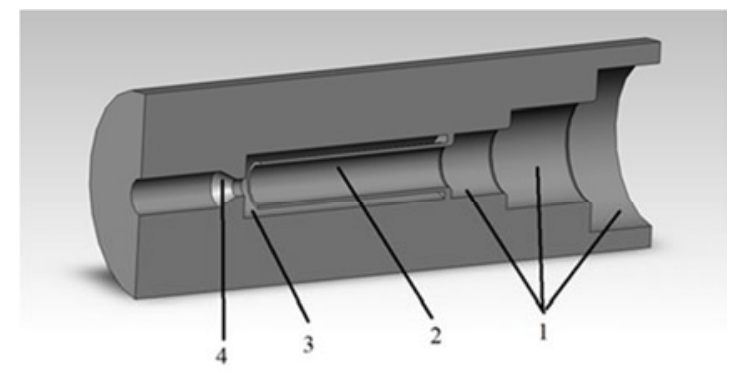

Fig. 2 A 3D model of the nozzle SN with a multi-diameter inlet [18]: 1 - multi-diameter inlet; 2 - oscillating chamber; 3 - expansion chamber; 4 - diffuser

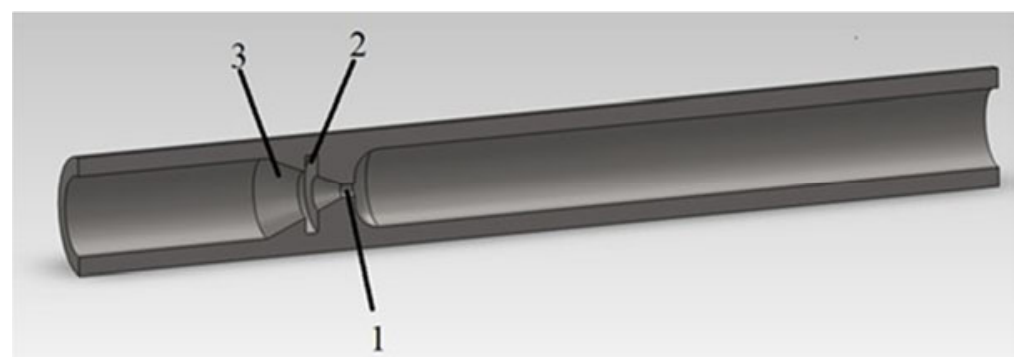

Fig. 3 A 3D model of the nozzle NECID [19] whose expansion chamber 2 is located inside the diffuser 3: 1 - contraction 


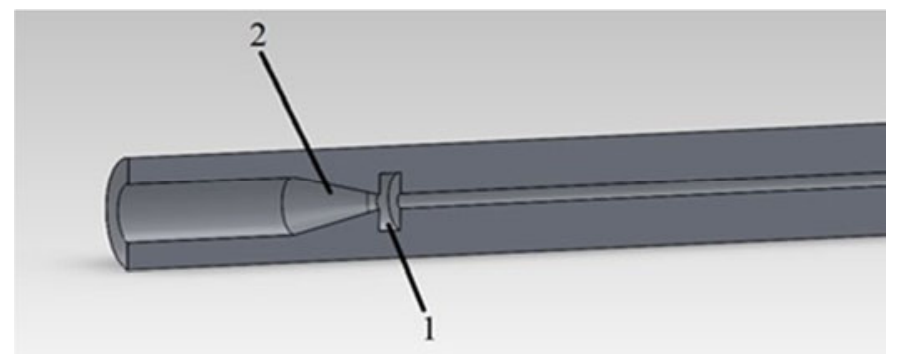

Fig. 4 A 3D model of the nozzle NECBD [20] whose expansion chamber 1 is located before the diffuser 2

\section{Materials and methods}

Three nozzles with different designs used to induce cavitation in a water jet were chosen as objects of numerical simulation. Figures 2-4 show 3D models of these nozzles.

The initial numerical simulation was carried out to establish the volume fraction of vapour generated by the nozzles as well as the distribution of gas bubbles in the water flow inside the nozzles. The distribution was important for determining the place where the bubbles begin to be formed since the cavitating liquid can cause erosive wear of inner surfaces of the nozzle.

The SolidWorks 2015 Flow Simulation software was used to establish the efficiency of nozzles. A Flow Simulation Engineering Cavitation model was used in this study. The study was conducted varying the pressure of supplied water from $4 \mathrm{MPa}$ to $10 \mathrm{MPa}$.

To evaluate the contaminant removal efficiency of the proposed technique, the cleanliness of finished (ground) flat aluminium surfaces was studied experimentally. Metal samples were machined with a medium soft white $\mathrm{Al}_{2} \mathrm{O}_{3}$ straight grinding wheel (grain size 250 , ceramic bonding material). After grinding, abrasive particles stuck to the aluminium surface were observed by an optical microscope and locations of these particles were marked. The machined samples were placed under the nozzle shown in Fig. 4 and every particle was processed by a cavitating pulsating water jet for 1 minute. Then, the metal surface was examined under the microscope again to determine the presence of particles on the surface. Every experiment was carried out with five particles and the particle removal efficiency values were established.

In the experiments, the small diameter of the diffuser of the nozzle (Fig. 4) was equal to $0.40 \mathrm{~mm}$ and other dimensions were as follows: the expansion chamber diameter was equal to $2.40 \mathrm{~mm}$, the expansion chamber length was equal to $1.20 \mathrm{~mm}$, the diffuser length was equal to $4.80 \mathrm{~mm}$, and the large diameter of the diffuser was equal to $2.40 \mathrm{~mm}$. The supplied water pressure was equal to $4 \mathrm{MPa}$ and the clearance between the nozzle outlet and the metal surface being cleaned was varied from $1 \mathrm{~mm}$ to $160 \mathrm{~mm}$.

\section{Results and discussion}

\subsection{Results of numerical simulation of cavitation inside the nozzles}

Vapour distribution inside the nozzles (Figs. 2-4) obtained for the supplied water pressures between 4 and $6 \mathrm{MPa}$ is shown in Figures 5-7. Other results were presented in the study [3]. Value 1 represents $100 \%$ volume concentration of vapour while value 0 represents $0 \%$. 

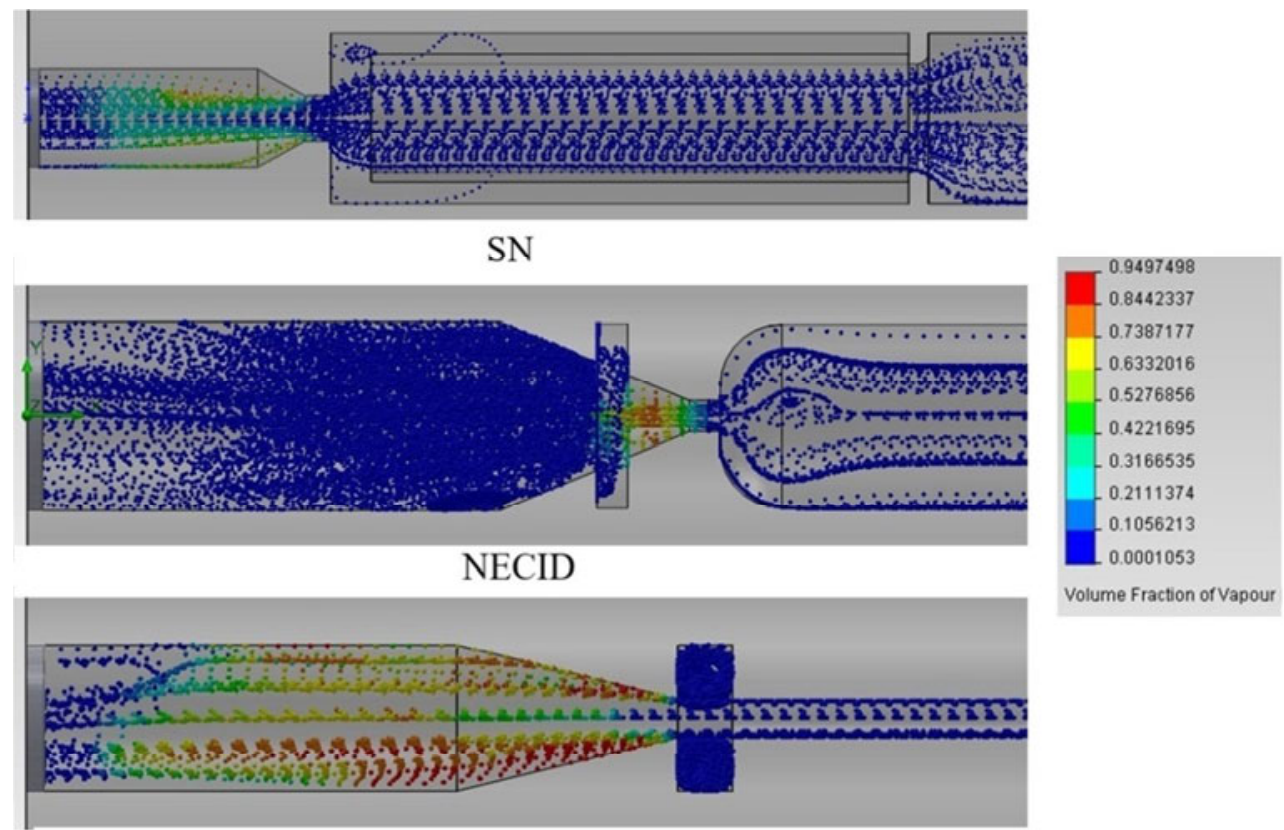

\section{NECBD}

Fig. 5 Vapour distribution in the nozzles (Figs. 2-4) when the supplied water pressure is equal to $4 \mathrm{MPa}$
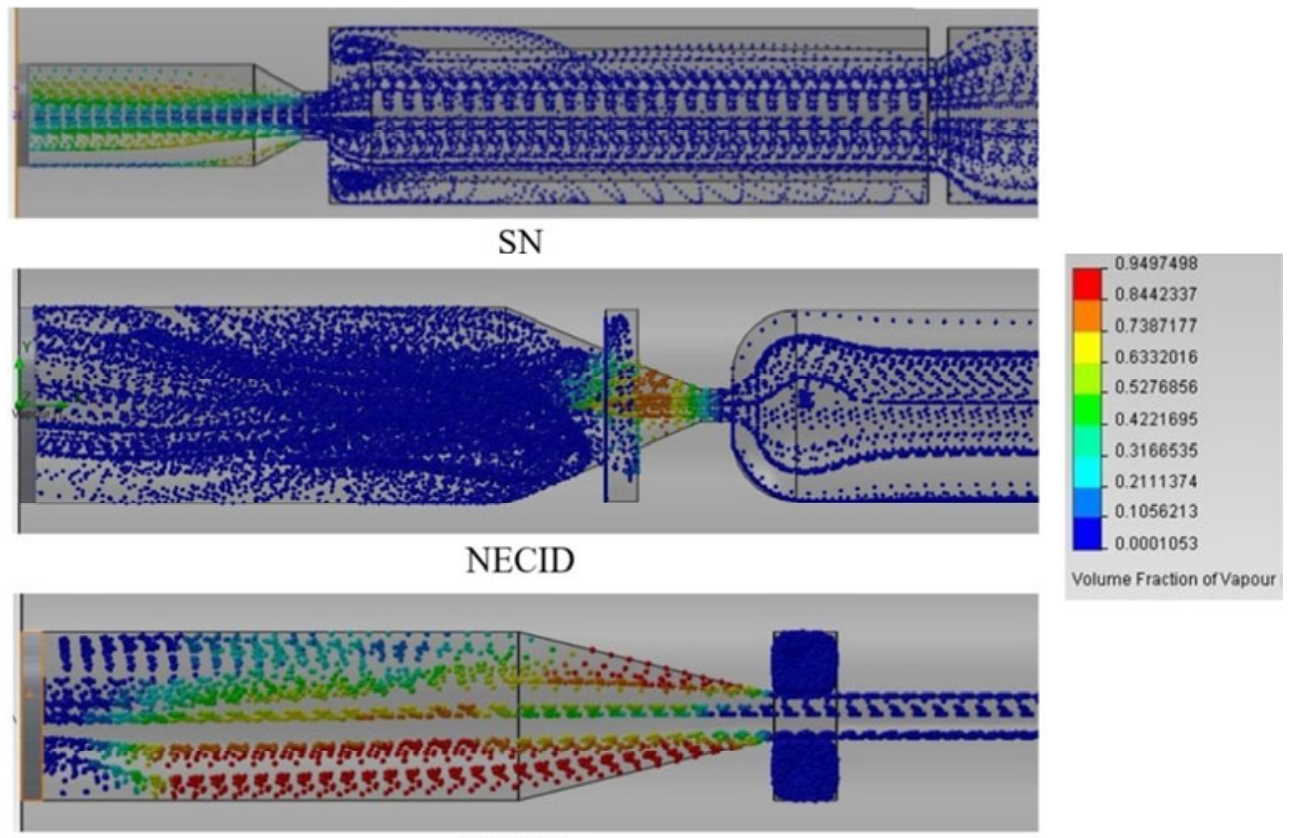

NECBD

Fig. 6 Vapour distribution in the nozzles (Figs. 2-4) when the supplied water pressure is equal to $5 \mathrm{MPa}$

Results of numerical simulation show that the nozzle NECBD (Fig. 4), whose expansion chamber is located before the diffuser, generates about $84-94 \%$ vapour near the outlet (Figs. 5-7, [3]). In addition, the results shown in Fig. 5 indicate that the nozzle NECBD generates the maximum amount of vapour (approximately $84 \%$ ) at the lowest supplied water pressure $(4 \mathrm{MPa})$.

The nozzles SN (Fig. 2) and NECBD (Fig. 4) produce the maximum amount of vapour near the nozzle outlet (Figs. 5-7, [3]). Thus, harmful erosive effects of cavitation on the nozzle material are minimised. However, the results of simulation [3] showed that the amount of vapour generated by the nozzle SN (Fig. 2) increases slightly with an increase in the supplied water pressure from $7 \mathrm{MPa}$ to $10 \mathrm{MPa}$. Therefore, the optimum water pressure in the case of 
the nozzle SN (Fig. 2) is $7 \mathrm{MPa}$. In the case of the nozzle NECBD (Fig. 4), the optimum water pressure can be reduced to $4 \mathrm{MPa}$. Taking into account that the nozzle NECBD (Fig. 4) has a simpler design than the nozzle SN (Fig. 2) and that it produces a greater amount of vapour, the nozzle NECBD was chosen for use in the proposed cleaning system (Fig. 1).
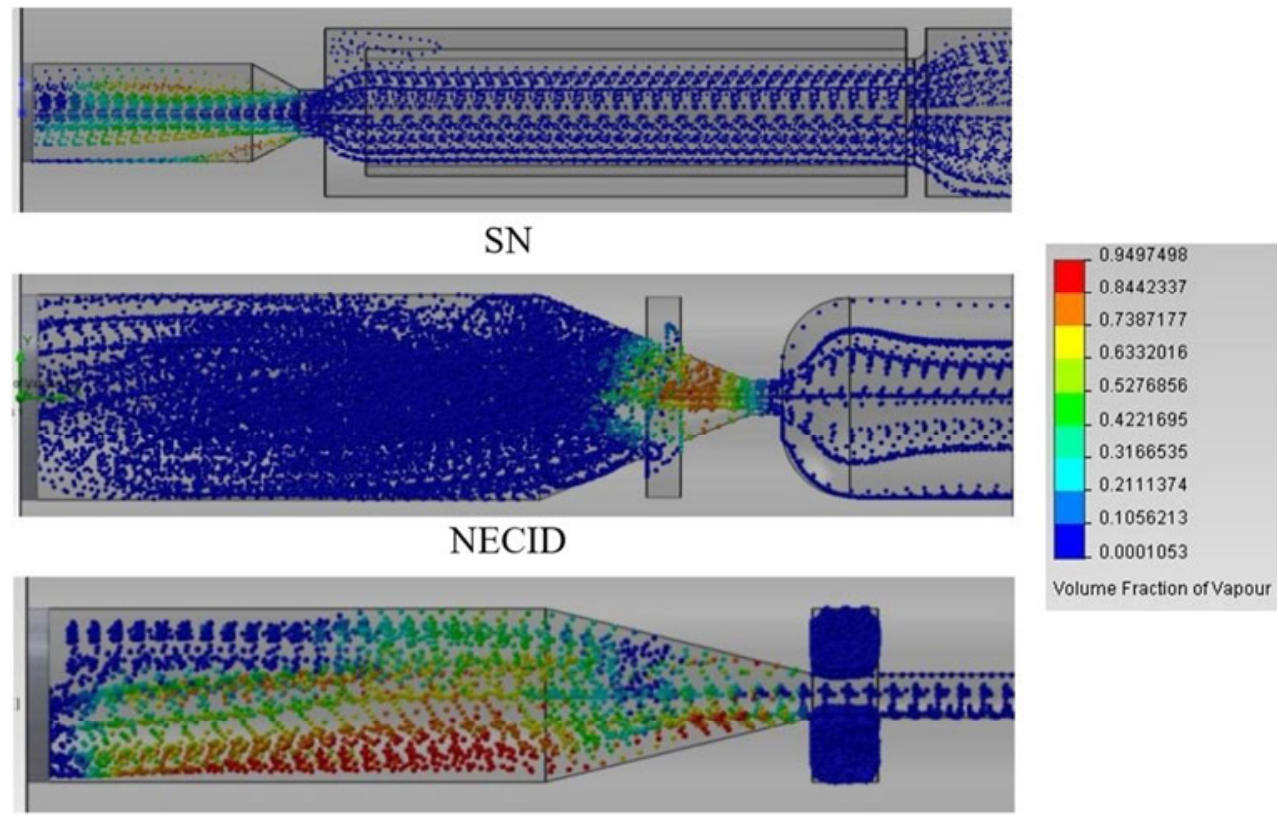

\section{NECBD}

Fig. 7 Vapour distribution in the nozzles (Figs. 2-4) when the supplied water pressure is equal to $6 \mathrm{MPa}$

\subsection{Experimental study into abrasive particle removal efficiency}

Experimental results are shown in Figure 8. As one can see in Figure 8, a 100\% particle removal efficiency is achieved if the clearance $l$ between the nozzle outlet and the surface being cleaned is equal to $1 \mathrm{~mm}$. If the supplied water pressure is reduced to $2 \mathrm{MPa}$, the maximum efficiency achieved is only $60 \%$ [3]. When the small diameter of the diffuser is increased from 0.4 to $0.8 \mathrm{~mm}$, the maximum removal efficiency is achieved at the $4 \mathrm{MPa}$ pressure and $1 \mathrm{~mm}$ distance $l$; however, in this case, it amounts to only $80 \%$ [3].

After performing the experiments, it was observed that water traces remain on the metal surface. These traces, which reduce the effectiveness of the proposed particle removal method, can be seen in Figure 9.

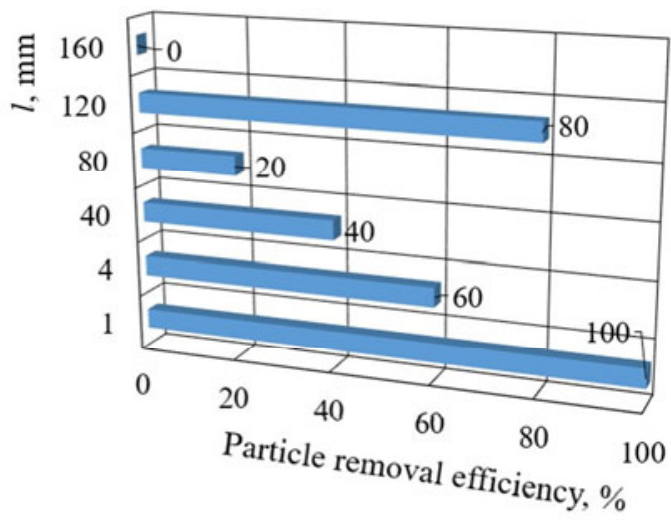

Fig. 8 Abrasive particle removal efficiency versus clearance $l$ between the nozzle NECBD outlet (Fig. 4) and the metal surface being cleaned (the supplied water pressure is $4 \mathrm{MPa}$, the small diameter of the nozzle diffuser is $0.4 \mathrm{~mm}$ ) 


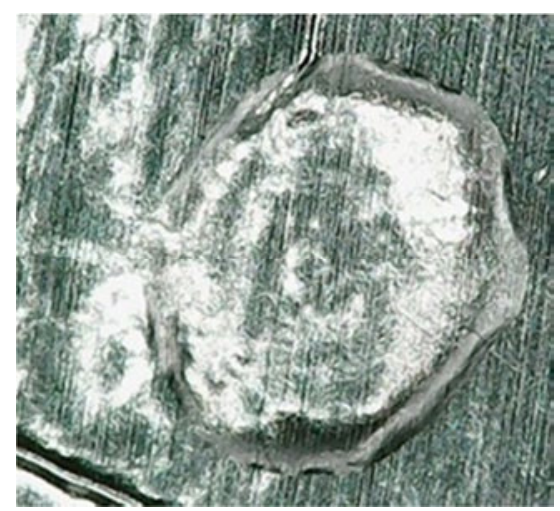

Fig. 9 Water traces on the aluminium surface that have remained after the cleaning process

3.3 Results of numerical simulation of flows inside cavitation-generating head with a water removal system

In order to solve the problem of water traces that have remained on the surface, a prototype of a cavitation generating head with a water removal system was developed. A 3D model of the head is shown in Figure 10.

The head works in a similar way to a cyclone separator: the air is tangentially supplied to the head, which forms a vortex. The rotating air flow creates a pulling force that catches the mass of water and contaminants from the surface being cleaned and removes it through the central part of the head (Fig. 11). To increase the removal efficiency, the vacuum effect is added to the top of the head.
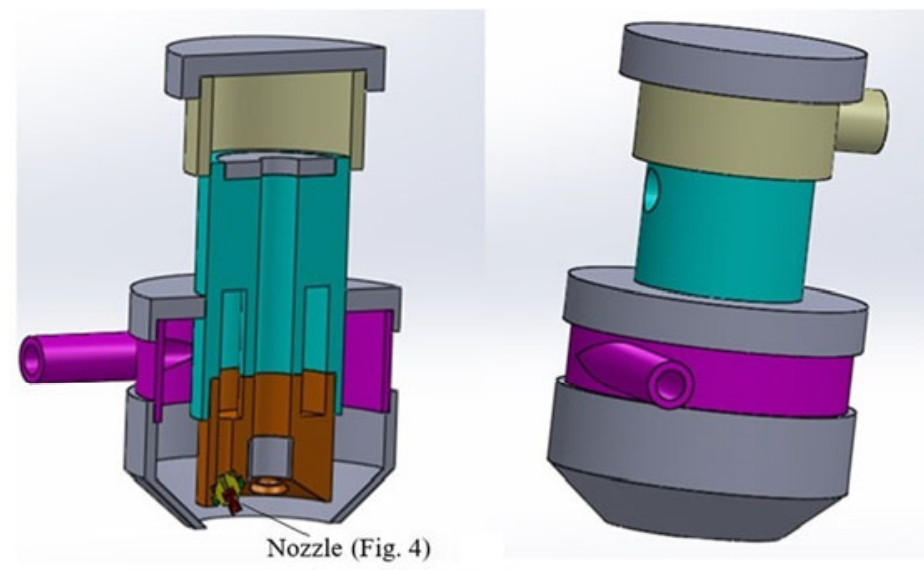

Fig. 10 A 3D model of cavitation-generating head with a water removal system

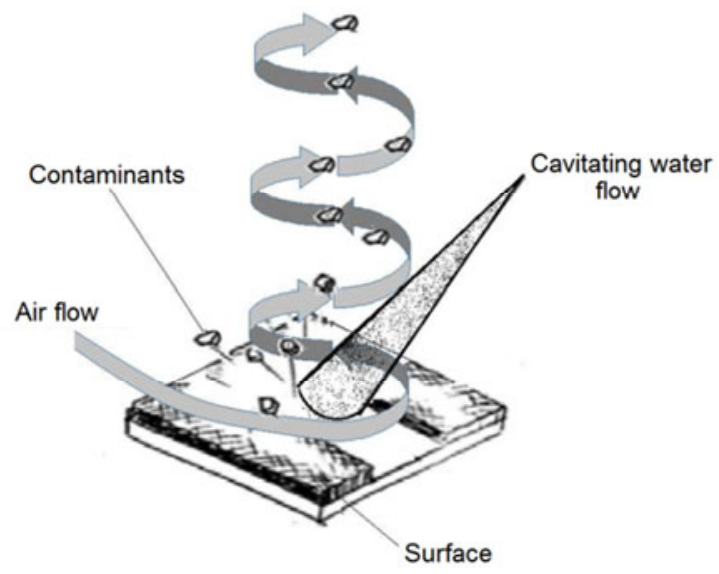

Fig. 11 A scheme of cavitation-generating head operation 
The SolidWorks 2015 Flow Simulation computer software was used for numerical simulation.

To simplify the calculations, the numerical study was performed in two steps:

1. Simulation of air flow inside the cavitation-generating head.

2. Simulation of cavitation process inside the cavitation-generating head.

It is necessary to determine the air flow parameters in order to simplify the numerical model of cavitation inside the head by introducing the boundary conditions obtained during the simulation of the supplied air flow. Table 1.

Initial and boundary conditions used in the numerical simulation of air flow are given in

Figure 12 shows the boundary conditions used in the simulation of the air flow supplied to the head. Simulation results are shown in Table 2 and Figure 13.

In Figure 13a one can see that the air pressure inside the head, in the area near the nozzles is equal to $101275.07 \mathrm{~Pa}$. This value was used as a boundary condition for the calculation of the cavitation parameters inside the chamber. The initial and boundary conditions used in the simulation of cavitation are given in Table 3. Figure 14 shows the boundary conditions for the cavitation-generating head.

Table 1 Initial and boundary conditions used in the numerical simulation of air flow

\begin{tabular}{|l|l|}
\hline \multicolumn{2}{|c|}{ Initial conditions } \\
\hline Thermodynamic parameters & $\begin{array}{l}\text { Static pressure: } 101325.00 \mathrm{~Pa} \\
\text { Temperature: } 293.20 \mathrm{~K}\end{array}$ \\
\hline Velocity & $\begin{array}{l}\text { Velocity vector components: } \\
\text { Velocity in the direction of X axis: } 0 \mathrm{~m} / \mathrm{s} \\
\text { Velocity in the direction of Y axis: } 0 \mathrm{~m} / \mathrm{s} \\
\text { Velocity in the direction of Z axis: } 0 \mathrm{~m} / \mathrm{s}\end{array}$ \\
\hline Fluid & Airflow supply parameters \\
\hline \multicolumn{2}{|c|}{ Air flow extraction parameters } \\
\hline Surface & Cross-section of the inlet \\
\hline Flow parameters & $\begin{array}{l}\text { Flow vector direction: normal to the surface } \\
\text { Flow rate: } 0.0023 \mathrm{~m} / \mathrm{s}\end{array}$ \\
\hline Thermodynamic parameters & $\begin{array}{l}\text { Approximate pressure: } 101325.00 \mathrm{~Pa} \\
\text { Temperature: } 293.20 \mathrm{~K}\end{array}$ \\
\hline Turbulence parameters & $\begin{array}{l}\text { Turbulence intensity: } 2.00 \% \\
\text { Turbulence length: } 0.003 \mathrm{~m}\end{array}$ \\
\hline Parameters of the boundary layer & $\begin{array}{l}\text { Flow vector direction: normal to the surface } \\
\text { Flow rate: } 0.0035 \mathrm{~m} / \mathrm{s}\end{array}$ \\
\hline Surface & $\begin{array}{l}\text { Approximate pressure: } 101325.00 \mathrm{~Pa} \\
\text { Temperature: } 293.20 \mathrm{~K}\end{array}$ \\
\hline Flow parameters & $\begin{array}{l}\text { Turbulence intensity: } 2.00 \% \\
\text { Turbulence length: } 0.003 \mathrm{~m}\end{array}$ \\
\hline Thermodynamic parameters & Type: Turbulent \\
\hline Parameters of the boundary layer & \\
\hline &
\end{tabular}




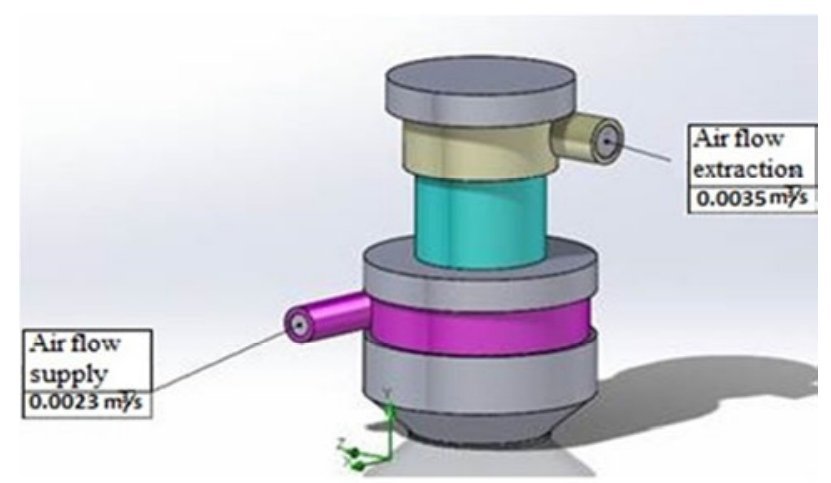

Fig. 12 A 3D model of a cavitation-generating head with boundary conditions used in the numerical simulation of air flow

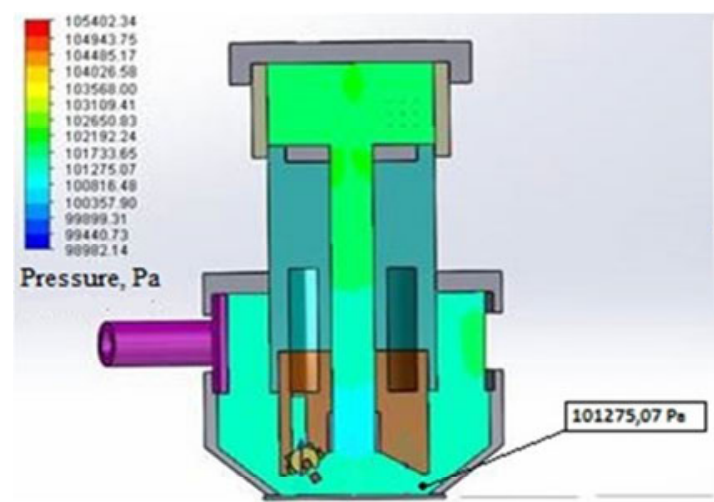

a)

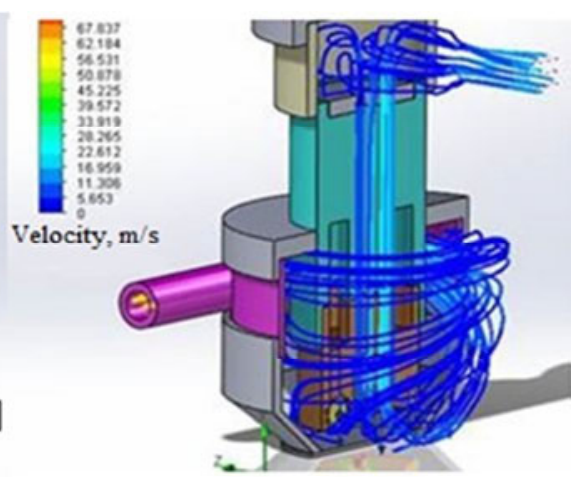

b)

Fig. 13 Air pressure distribution (a) and air flow trajectories (b) inside the cavitation-generating head.

Table 2 Air flow numerical simulation results

\begin{tabular}{|l|c|c|}
\hline \multirow{2}{*}{ Name of the parameter } & \multicolumn{2}{|c|}{ Value } \\
\cline { 2 - 3 } & Minimum & Maximum \\
\hline Pressure, $\mathrm{Pa}$ & 98982.14 & 105402.34 \\
\hline Temperature, $\mathrm{K}$ & 288.48 & 297.67 \\
\hline Velocity, $\mathrm{m} / \mathrm{s}$ & 0 & 79.143 \\
\hline Velocity component along the $\mathrm{X}$ axis, $\mathrm{m} / \mathrm{s}$ & -79.099 & 8.204 \\
\hline Velocity component along the $\mathrm{Y}$ axis, $\mathrm{m} / \mathrm{s}$ & -11.079 & 31.911 \\
\hline Velocity component along the $\mathrm{Z}$ axis, $\mathrm{m} / \mathrm{s}$ & -46.880 & 18.188 \\
\hline Mach number & 0 & 0.23 \\
\hline Density, $\mathrm{kg} / \mathrm{m}^{3}$ & 1.18 & 1.25 \\
\hline Shear stresses, $\mathrm{Pa}$ & 0 & 26.54 \\
\hline
\end{tabular}




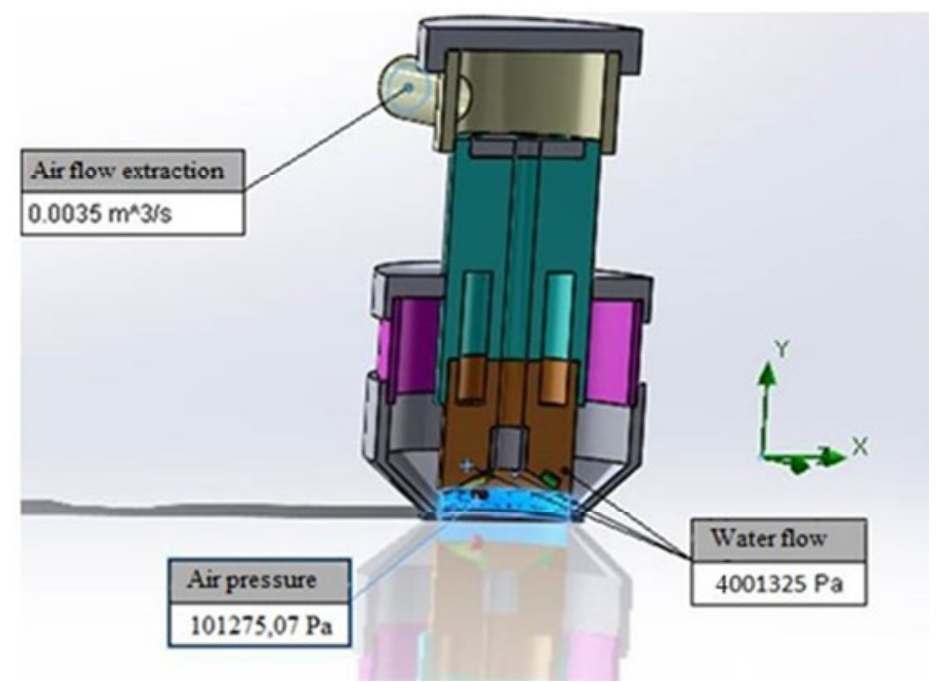

Fig. 14 A 3D model of cavitation-generating head with initial and boundary conditions used in the simulation of cavitation process

Table 3 Initial and boundary conditions used in the numerical simulation of cavitation process

\begin{tabular}{|l|l|}
\hline \multicolumn{2}{|c|}{ Initial conditions } \\
\hline Thermodynamic parameters & $\begin{array}{l}\text { Static pressure: } 101325.00 \mathrm{~Pa} \\
\text { Temperature: } 293.20 \mathrm{~K}\end{array}$ \\
\hline Velocity parameters & $\begin{array}{l}\text { Velocity vector components: } \\
\text { Velocity in the direction of X axis: } 0 \mathrm{~m} / \mathrm{s} \\
\text { Velocity in the direction of Y axis: } 0 \mathrm{~m} / \mathrm{s} \\
\text { Velocity in the direction of Z axis: } 0 \mathrm{~m} / \mathrm{s}\end{array}$ \\
\hline Thermodynamic parameters & $\begin{array}{l}\text { Static pressure: } 101325.00 \mathrm{~Pa} \\
\text { Temperature: } 293.20 \mathrm{~K}\end{array}$ \\
\hline Fluid & Water \\
\hline Surface & Water supply parameters \\
\hline Parameters of the flow & Cross-sections of the nozzle outlet \\
\hline Thermodynamic parameters & $\begin{array}{l}\text { Flow vector direction: normal to the surface } \\
\text { Water flow pressure: } 4001325.0 \mathrm{~Pa}\end{array}$ \\
\hline Turbulence parameters & $\begin{array}{l}\text { Approximate pressure: } 101325.0 \mathrm{~Pa} \\
\text { Temperature: } 293.20 \mathrm{~K}\end{array}$ \\
\hline Parameters of the boundary layer & $\begin{array}{l}\text { Turbulence intensity: } 2.00 \% \\
\text { Turbulence length: } 0.003 \mathrm{~m}\end{array}$ \\
\hline \multicolumn{1}{|c|}{ Flow extraction parameters } \\
\hline Surface & Cross-section of the outlet \\
\hline Parameters of the flow & $\begin{array}{l}\text { Flow vector direction: normal to the surface } \\
\text { Flow rate: } 0.0035 \mathrm{~m} / \mathrm{s}\end{array}$ \\
\hline Thermodynamic parameters & $\begin{array}{l}\text { Approximate pressure: } 101325.0 \mathrm{~Pa} \\
\text { Temperature: } 293.20 \mathrm{~K}\end{array}$ \\
\hline Turbulence parameters & $\begin{array}{l}\text { Turbulence intensity: } 2.00 \% \\
\text { Turbulence length: } 0.003 \mathrm{~m}\end{array}$ \\
\hline Parameters of the boundary layer & Type: Turbulent \\
\hline
\end{tabular}




\begin{tabular}{|l|l|}
\hline \multicolumn{2}{|c|}{ Parameters of the air flow inside the head } \\
\hline Surface & Cross-section of the cleaning chamber \\
\hline Parameters of the flow & $\begin{array}{l}\text { Flow vector direction: normal to the surface } \\
\text { Pressure: } 101275.07 \mathrm{~Pa}\end{array}$ \\
\hline Thermodynamic parameters & $\begin{array}{l}\text { Approximate pressure: } 101325.0 \mathrm{~Pa} \\
\text { Temperature: } 293.20 \mathrm{~K}\end{array}$ \\
\hline Turbulence parameters & $\begin{array}{l}\text { Turbulence intensity: } 2.00 \% \\
\text { Turbulence length: } 0.003 \mathrm{~m}\end{array}$ \\
\hline Parameters of the boundary layer & Type: Turbulent \\
\hline
\end{tabular}

Simulation results are summarized in Table 4. Flow trajectories and vapour distribution on the surface being cleaned are given in Figures 15 and 16.

In Figure 15 one can see that the flow follows the same trajectory as that obtained in the air flow simulation (Fig. 13b).

Table 4 Results of the cavitation process numerical simulation

\begin{tabular}{|l|c|c|}
\hline \multirow{2}{*}{ Name of the parameter } & \multicolumn{2}{|c|}{ Value } \\
\cline { 2 - 3 } & Minimum & Maximum \\
\hline Pressure, $\mathrm{Pa}$ & 1329.83 & 21100000 \\
\hline Temperature, $\mathrm{K}$ & 280.78 & 303.07 \\
\hline Velocity, $\mathrm{m} / \mathrm{s}$ & 0 & 483.243 \\
\hline Velocity component along the X axis, $\mathrm{m} / \mathrm{s}$ & -313.584 & 310.952 \\
\hline Velocity component along the Y axis, $\mathrm{m} / \mathrm{s}$ & -387.125 & 292.817 \\
\hline Velocity component along the Z axis, $\mathrm{m} / \mathrm{s}$ & -271.435 & 37.371 \\
\hline Volume fraction of vapour & 0 & 0.949 \\
\hline Mach number & 0 & 118.06 \\
\hline Density, $\mathrm{kg} / \mathrm{m}^{3}$ & 9.81 & 1017.36 \\
\hline Shear stresses, Pa & 0 & 40793.17 \\
\hline
\end{tabular}

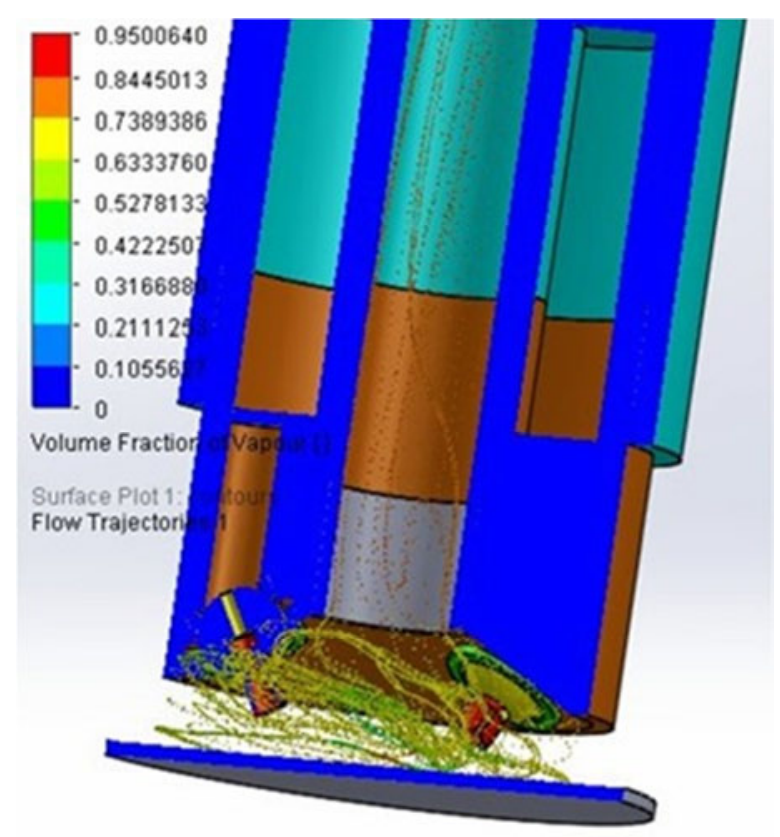

Fig. 15 Water flow trajectories inside the cavitation-generating head 


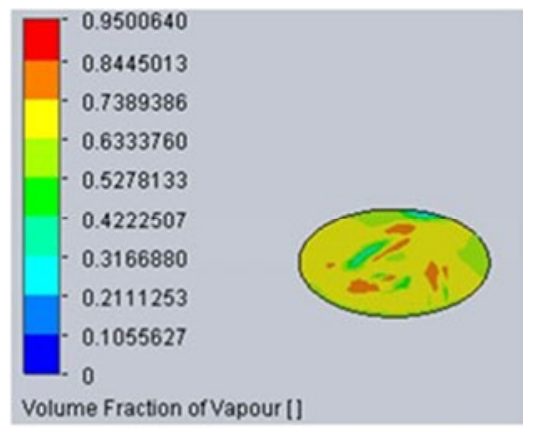

Fig. 16 Arrangement of cavitation clouds on the surface being cleaned

Figure 16 shows the distribution of volume fraction of vapour (cavitation clouds) on the surface being cleaned. One can see that there are places on the surface where the fraction of vapour reaches $84 \%$, which testifies to the presence of intensive cavitation zones on the surface.

\section{Conclusions}

The nozzle whose expansion chamber is located before the diffuser exhibits optimum properties required for the cleaning of surfaces with a cavitating pulsating water jet. The nozzle combines a simple design with a less strong self-erosive impact and generates the maximum amount of vapour (approximately $84 \%$ by the volume of flow) at a relatively low pressure of $4 \mathrm{MPa}$ of supplied water.

Simulation results indicate that the behaviour of the cavitating water flow inside the cavitation-generating head can be investigated numerically.

After performing the numerical simulation of water and air flows inside the cavitationgenerating head, it was established that the cavitating flow trajectory coincides with the air flow trajectory. It was also established that there are places on the surface being cleaned where the concentration of water vapour reaches $84 \%$, which testifies to the presence of intense cavitation zones.

\section{REFERENCES}

[1] W.T. Tsai: A review of environmental hazards and adsorption recovery of cleaning solvent hydrochlorofluorocarbons (HCFCs), J Loss Prevent Proc, 15, 2, 2002, 147-157. https://doi.org/10.1016/S0950-4230(01)00023-7

[2] D. Dursun, F. Sengul: Waste minimization study in a solvent-based paint manufacturing plant, Resour Conserv Recy, 47, 4, 2006, 316-331. https://doi.org/10.1016/j.resconrec.2005.12.004

[3] A. Ralys, V. Striška and V. Mokšin: Selection of the nozzle for metal surface cleaning using cavitating pulsing fluid flow, Solid State Phenom, 220-221, 2015, 957-962. https://doi.org/10.4028/www.scientific.net/ssp.220-221.957

[4] K.H. Kim, G.L. Chahine, J.P. Franc and A. Karimi: Advanced Experimental and Numerical Techniques for Cavitation Erosion Prediction, Springer Netherlands, Dordrecht, 2014. https://doi.org/10.1007/978-94-017-8539-6_1

[5] J. Lu, S. Yuan, P. Siva, J. Yuan, X. Ren and B. Zhou: The characteristics investigation under the unsteady cavitation condition in a centrifugal pump, J Mech Sci Technol, 31, 3, 2017, 1213-1222. https://doi.org/10.1007/s12206-017-0220-3

[6] G. Wang, Q. Wu and B. Huang: Dynamics of cavitation-structure interaction, Acta Mech Sin, 33, 4, 2017 , 685-708. https://doi.org/10.1007/s10409-017-0685-4

[7] S. Parthasarathy, R.R. Mohammed, C.M. Fong, R.L. Gomes and S. Manickam: A novel hybrid approach of activated carbon and ultrasound cavitation for the intensification of palm oil mill effluent (POME) polishing, J Clean Prod, 112, 2016, 1218-1226. https://doi.org/10.1016/j.jclepro.2015.05.125 
[8] Y. Caliskan, H. Yatmaz Cengiz and N. Bektas: Photocatalytic oxidation of high concentrated dye solutions enhanced by hydrodynamic cavitation in a pilot reactor, Process Saf Environ Prot, 111, 2017, 428-438. https://doi.org/10.1016/j.psep.2017.08.003

[9] G.L. Chahine, A. Kapahi, C.T. Hsiao and J.K. Choi: Coupling bubble and material dynamics to model cavitation peening and pitting, $J$ Fluid Sci Tech, 11, 4, 2016, 1-15. https://doi.org/10.1299/jfst.2016jfst0023

[10] B. Niemczewski: Observations of water cavitation intensity under practical ultrasonic cleaning conditions, Ultrason Sonochem, 14, 1, 2007, 13-18. https://doi.org/10.1016/j.ultsonch.2005.11.009

[11] H.E. Cheng-long, W. U. Jian-hua and L. U. Wen-li: Research progress of the cavitation application, $J$ Jiaxing Univ, 20, 3, 2008, 57-62.

[12] H. Soyama: Improvement in fatigue strength of silicon manganese steel SUP7 by using a cavitating jet, JSME Int J A-Solid M, 43, 2, 2000, 173-178. https://doi.org/10.1299/jsmea.43.173

[13] G.E. Qiang, L.I. Xiao-hong, L.U. Yi-yu and T. Yong: Mechanism of organic wastewater treatment by cavitating jets, $J$ Chongqing Univ, 30, 5, 2007, 49-53.

[14] L. Gensheng, S. Zhonghou: Cavitation jet and the application on the drilling engineering, Petroleum Drilling Techniques, 24, 4, 1996, 51-54.

[15] P. Arbab, B. Ayati and M. R. Ansari: Reducing the use of nanotitanium dioxide by switching from single photocatalysis to combined photocatalysis-cavitation in dye elimination, Process Saf Environ Prot, 121, 2019, 87-93. https://doi.org/10.1016/j.psep.2018.10.012

[16] A.N. Livanskiy, V.M. Prikhodko, S.K. Sundukov and D.S. Fatyukhin: Research on the influence of ultrasonic vibrations on paint coating properties, $T$ Famena, 40, 1, 2016, 129-138.

[17] M. Yang, S. Xiao, C. Kang and Y. Wang: Effect of geometrical parameters on submerged cavitation jet discharged from profiled central-body nozzle, Chin J Mech Eng, 26, 3, 2013, 476-482. https://doi.org/10.3901/cjme.2013.03.476

[18] V.E. Johnson: Enhancing Liquid Jet Erosion, U.S. Patent 4,474,251, 1984.

[19] I. Kondratayev, J. Fulkerson, I. Kamenkov and V.A. Paramygin: Nozzle for Generating High-Energy Cavitation, U.S. Patent 2009/0072043A1, 2009.

[20] I. Kondratiev, J. Fulkerson and I. Kamenkov: Nozzle for Generating High-Energy Cavitation, U.S. Patent 2004/0245356A1, 2004.

Submitted: $\quad$ 18.3.2019

Accepted: $\quad$ 16.9.2019 lect. Aurimas Ralys, M. Sc. prof. Vadim Mokšin*, Ph. D.

Vilnius Gediminas Technical University Faculty of Mechanics Department of Mechanical and Material Engineering

J. Basanavičiaus str. 28 03224 Vilnius, Lithuania *corresponding author, vadim.moksin@vgtu.lt 